\title{
1 Analysis of earthquake-induced groundwater level change using self-organizing maps
}

2

3 Kei Nakagawa* $\cdot$ Zhi-Qiang Yu $\cdot$ Ronny Berndtsson $\cdot$ Makoto Kagabu

4

$5 \quad$ Kei Nakagawa $(\square)$, Makoto Kagabu

6 Institute of Integrated Science and Technology, Nagasaki University,

7 1-14 Bunkyo-machi, Nagasaki 852-8521, Japan

8 e-mail: kei-naka@ nagasaki-u.ac.jp

$9 \quad$ Tel.: +8195819 2763; fax: +81958192763

$10 *$ corresponding author

12 Zhi-Qiang Yu

13 Graduate School of Fisheries and Environmental Sciences, Nagasaki University,

14 1-14 Bunkyo-machi, Nagasaki 852-8521, Japan

16 Ronny Berndtsson

17 Division of Water Resources Engineering \& Center for Middle Eastern Studies, Lund University, 


\section{$21 \quad$ Abstract}

22 For a better understanding of possible physical links between geophysical observables and earthquake

23 characteristics, it is important to analyze statistical spatiotemporal patterns in nature related to such events.

24 For this purpose, characteristic changes in groundwater level (GWL) were observed before and after the 2016 Kumamoto earthquake in Japan. Previous research has shown that self-organizing maps (SOM) can be used to classify complex patterns of GWL-change during different parts of the earthquake sequence. In this study, we used before and after earthquake GWL data as input vectors to SOM. In total, 64 observed groundwater levels were classified into 12 different clusters. Most shallow wells displayed GWL difference that was small during the foreshock (first earthquake) and large during the main-shock (second earthquake). Upstream deep wells showed relatively large difference in water level from 1 to 2 days after the earthquakes.

31 The GWL rapidly increased just after the earthquake, then tended to gradually decrease from September. Most of the shallow wells in the unconfined aquifer rapidly recovered to initial GWLs within several hours to several days, because of hydrostatic pressure. However, most of the deep wells in the confined aquifer needed longer time to recover, in some cases several weeks to several months. These findings are important for the physical understanding of earthquake effects on the groundwater environment, disaster prevention, and possibility for development of earthquake precursors.

\section{Keywords}




\section{Introduction}

The 2016 Kumamoto earthquake sequence started with a $6.2 \mathrm{M}_{\mathrm{W}}$ foreshock at 21:26 (JST) on April 14.

About 28 hours later, it culminated in a 7.0 Mw main-shock tremor at 1:25 (JST) on April 16. The strike-

44 slip movement of the seismogenic Hinagu-Futagawa fault is the main cause of this type of crustal earthquakes in the area. The earthquake triggered a series of natural disasters such as surface ruptures, landslides, land subsidence, liquefaction, which resulted in severe damage to infrastructure and buildings in the epicenter region, especially in Mashiki town and Minami-Aso village (Shirahama et al. 2016; Yamazaki and Liu 2016).

Hydrological effects occur simultaneously with seismic processes in earthquake-affected areas. Such effects may be liquefaction, groundwater level (GWL) anomalies, changes in water chemistry, formation or depletion of springs, streamflow variation, and eruption of mud volcanoes (Wang and Manga 2010; Manga and Wang 2015; Shi et al. 2015). During the last decades, with the development of efficient observation techniques, such phenomena are quantitatively recorded and analyzed for a better physical understanding, disaster prevention, and possible development of earthquake precursors (Roeloffs 1988; Tsunogai and Wakita 1995; Barberio et al. 2017). Especially, with respect to GWL effects, there have been many correlational studies. For example, (1) detailed observations of GWL-change types induced by one or multiple earthquakes (Chia et al. 2001, 2008; Cox et al. 2012; Shi et al. 2015), (2) mechanism assessment of GWL-change characteristics through interdisciplinary methods such as poroelastic theory, permeability enhancement, and undrained consolidated sediments (Wang and Chia 2008; Wang and Manga 2010; Manga and Wang 2015), and (3) numerical modeling using correlation between earthquake-triggered GWL- 
variation recovery and hydrogeological characteristics in different aquifers (Lin et al. 2018).

For an improved understanding of links between earthquakes and sub-surface hydrological processes, research has focused on the 2016 Kumamoto earthquake by applying various methods. Hosono et al. (2018) interpreted earthquake-induced structural deformation causing hydrologic response in the active volcanic system of the Mount Aso caldera. It clarified the source mechanism for new spring formation and assessment of hydrothermal solute fluxes by use of hydrogeochemistry, isotopes, and binary mixing calculations, respectively. Drinking water for habitants in the Kumamoto area is almost $100 \%$ from groundwater. Thus, this area has been equipped by a high-resolution and extensive monitoring system in groundwater wells for water quality, withdrawal, and hydrologic response to earthquakes. These data provide a unique opportunity to study how crustal earthquakes influence hydrological processes in the nearzone of earthquakes (within one rupture distance).

Recently, multivariate analysis using self-organizing maps (SOM) has been applied in various research fields, such as ecology, geomorphology, hydrology, meteorology, and wastewater treatment. SOM is an effective tool for studying and interpreting of spatiotemporally varying phenomena (Kalteh and Berndtsson 2007; Bedoya et al. 2009; Yu et al. 2014; Nguyen et al. 2014, 2015; Nakagawa et al. 2017; Yu et al. 2018). Using SOM, visual representation of complex but linked groundwater characteristics is possible. Ishihara et al. (2013) used SOM to evaluate GWL characteristics in Tokyo induced by the 2011 off the Pacific coast of Tohoku earthquake. Eight patterns were identified for the characteristics of unconfined and confined aquifer GWL-change. They concluded that SOM successfully characterized GWL fluctuation patterns affected by the earthquake. 

In view of the above, this study deals with characteristic changes in GWL that were observed after the 2016 Kumamoto earthquake. The objectives are to improve the understanding regarding GWL

83 effects due to seismic activities and give practical recommendations to groundwater supply managers

84 regarding expected time scale of GWL changes in connection to earthquakes. For this purpose, SOM combined with hierarchical cluster analysis using before and after earthquake GWL data as input vectors

86 are applied. The classification results obtained by the SOM analyses, the spatiotemporal properties of

87 GWL-change, and seismic relationships are discussed in detail. The paper is closed by a discussion on practical advice to groundwater supply managers.

\section{Materials and methods}

\section{Study area}

92 Kumamoto area is located in the center of Kyushu Island, southern Japan. It occupies an area of $945 \mathrm{~km}^{2}$.

93 The main geology is constituted by Paleozoic bedrock of metamorphic and sedimentary rock, pre-Aso

94 volcanic rock of Tertiary-Quaternary period, Quaternary Aso volcanic rock, and lacustrine alluvium. Pre-

95 Aso volcanic rock has evolved as lava and tuff breccia. However, Quaternary Aso volcanic rocks are mainly

96 pyroclastic deposits from four eruptions of the Aso volcano, named Aso-1 (270 ka), Aso-2 (140 ka), Aso-3

97 (120 ka), and Aso-4 (89 ka), respectively (Miyoshi et al. 2009; Hosono et al. 2013). These pyroclastic

98 deposits as well as part of the alluvial deposits contain important aquifers. The uppermost Aso-4 and alluvial

99 sediments include a near-surface unconfined aquifer with uneven thickness ranging from a few meters to

$10050 \mathrm{~m}$. Aso-1, Aso-2, and Aso-3 contain confined aquifers with a varying thickness of 60-200 m. The 
101 discontinuous lacustrine deposits and marine sediments act as an aquiclude between the aquifers (Kagabu

102 et al. 2017)

Locations of the 19 shallow and 45 deep wells acting as the monitoring system in this study is

104 shown in Fig. 1. These monitoring wells are distributed over the Kumamoto groundwater area consisting

105 of the Shirakawa and Midorikawa River watersheds. The regional climate is warm and humid. Mean annual

106 temperature and precipitation are about $16.9^{\circ} \mathrm{C}$ and $1986 \mathrm{~mm}$, respectively. About $40 \%$ of the rainfall occur

107 from June to July (Japan Meteorological Agency 2018).

conducted such as combined use of isotopes for confirming nitrate origin (from chemical fertilizer,

110 wastewater, and manure), attenuation mechanisms and identifying nitrate biogeochemical processes with

111 regional groundwater flow (Hosono et al. 2013, 2014), evaluation of groundwater age by using multiple

112 environmental tracers (Kagabu et al. 2017), and understanding the origin of fluoride, arsenic pollution, and

113 cumulative environmental factors for groundwater quality (Hossain et al. 2016a, b). These studies have

114 significantly contributed to groundwater quality protection and basis for policy decisions in the study area.

115 At the same time, these studies provide an important background knowledge for a detailed understanding

116 of groundwater processes in the area.

\section{Self-organizing maps}

119 Self-organizing maps (SOM) are powerful tools for spatiotemporal data analyses (Nguyen et al. 2015;

120 Nakagawa et al. 2017). During recent decades SOM have been used in a multitude of research fields (e.g., 
121 Kalteh and Berndtsson 2007; Bedoya et al. 2009; Yu et al. 2014; Nguyen et al. 2014, 2015; Nakagawa et

122 al. 2017; Yu et al. 2018). The advantage of SOM is that high-dimensional and complex data can be projected

123 onto a more easily interpreted two-dimensional hexagonal array. Similarity of extracted SOM patterns is

124 then compared visually using color gradients. The objective of SOM applications is to obtain useful and

125 physically explainable reference vectors. The SOM properties also mean that a larger map size will give a

126 higher resolution for pattern recognition. Optimal number of nodes and map configuration are determined

127 by $m=5 \sqrt{n}$, where $m$ represents the number of map nodes and $n$ the number of input data (Hentati et al.

128 2010). The number of rows and columns is dependent on the square root of the ratio between the two largest

129 eigenvalues of transformed data (García and González 2004). These eigenvalues are calculated by principal

130 component analysis (PCA). The reference vectors are obtained after iterative updates through a training

131 phase that is composed by three main procedures: competition between nodes, selection of a winner node,

132 and updating of the vectors. Results of the analysis are achieved after the training phase, which is fine-

133 tuned using cluster analysis such as k-means algorithms (Jin et al. 2011). Davies-Bouldin Index (DBI),

134 applying k-means algorithms, determines the optimal number of clusters (García and González 2004). In

135 the present study, these calculations were made using a modified version of SOM Toolbox 2.0 (Vesanto et

136 al. 2000).

137

138 Data

139 Six kinds of GWL data were used as input vectors to the SOM analyses. As mentioned above, the

140 earthquake was composed of two shocks; foreshock (first earthquake) on April 14 and main-shock (second 
141 earthquake) on April 16. The GWL data were taken from the groundwater monitoring network at hourly

142 auto-recorded time intervals and transferred to an administrative center. Before applying the SOM analysis,

143 data were organized according to the sequence of foreshock and main-shock. The earthquake-affected GWL

144 time sequences used in the analyses are shown in Fig. 2. According to Fig. 2, (1) GWL difference between

145 before and after foreshock (April 14, 22:00 (B) - 21:00 (A)) denoted F(a): (B-A), (2) GWL difference

146 between 22 hours and right after foreshock (April 15, 20:00 (C) - April 14, 22:00 (B)) denoted F(b): (C-B),

147 (3) GWL difference between 2 days and 1 day after foreshock (average for April 16 (E) - April 15, 21:00

148 (D)) denoted F(c): (E-D), and (4) M(a) to M(c) are analogously defined as F(a) to F(c) as M(a): (G-F) GWL

149 difference between before and after main-shock on April 16, 2:00 (G) - 1:00 (F). M(b): (H-G) is the GWL

150 difference after 22 hours and right after main-shock on April 16, 23:00 (H) - 2:00 (G). M(c): (J-I) is the

151 GWL difference between 2 days and 1 day after main-shock. The averaged GWL on April 18 (average) (J)

152 - April 17, 1:00 (I). Using these defined six time series variables (F(a), F(b), F(c), M(a), M(b), and M(c))

153 served as input vectors to explore the spatiotemporal GWL-change characteristics for each observation 154 location.

\section{Results and discussion}

157 Time series variation of reference vectors

158 The time series variation of reference vectors is shown in Fig. 3. The upper row represents the GWL change

159 features during the foreshock, and the lower row shows the GWL change characteristics during the main-

160 shock. A comparison between $\mathrm{F}(\mathrm{a})$ and $\mathrm{F}(\mathrm{b}), \mathrm{M}(\mathrm{a})$ and $\mathrm{M}(\mathrm{b})$, lower located neurons (reference vectors) 
161 displayed large GWL difference with a time lag of 22 hours. As well, F(b) and M(b) displayed a similar

162 time variation. The behavior right after and 22 hours after the earthquakes was similar for both foreshock

163 and main-shock. This means that both earthquakes had generally similar change characteristics for

164 groundwater levels during this period (within 22 hours) for most of the monitoring wells. In addition, F(c)

165 showed larger neuron changes than $\mathrm{M}(\mathrm{c})$. The reason for this is the superimposed effect of foreshock and

166 main-shock for $F(c)$. Besides using the defined six variables (F(a), $F(b), F(c), M(a), M(b)$, and $M(c))$, the

167 spatial variation characteristics of GWL difference are further explored in Fig. 4. The GWL change of M(a)

168 is larger than $\mathrm{F}(\mathrm{a})$, because the main-shock formed a series of new faults and the increasing of seismic

169 energy density. In addition, the GWL change of $\mathrm{F}(\mathrm{c})$ is also greater than $\mathrm{M}(\mathrm{c})$, as to the above discussion

170 of superimposed effect. The general change characteristics of GWL difference is basically consistent with

171 the SOM change features.

\section{Cluster analysis}

174 The cluster analysis using the SOM reference vectors resulted in 12 clusters as shown in Fig. 5. The number

175 of clusters was determined through the DBI index as explained above. Accordingly, the minimum DBI

176 corresponds to the optimal number of clusters, which was equal to 12 in this case. The number labeled for

177 each reference vector corresponds to the number of observation wells classified into the vector. According

178 to the dendrogram (Fig. 6), the number of parent clusters are 5 (distance of about 3.5). In this case, clusters groups. No well locations were classified into cluster 10. Thus, this cluster was excluded from further 
181 analysis. The unconfined aquifer wells were classified into clusters 1, 5, 9 and 11 that include 3, 7, 8, and

1821 well, respectively. The main reason why we are not able to separate confined and unconfined wells before

183 using SOM classification, is that unconfined well data are limited to only 19 wells.

\section{Radar-charts of clusters}

Radar-charts for each cluster display the main characteristics of the input data as displayed in Fig. 7. Cluster

1 is related to the downstream of Shirakawa and Midorikawa River watersheds 6 locations, $F(b)$ and $M(b)$ are quite small but on the other hand $\mathrm{F}(\mathrm{a})$ and $\mathrm{M}(\mathrm{a})$ are large. The GWL difference was small right after and 22 hours after the earthquake. The GWL difference was large before and after the earthquake.

191 represented by deep wells $(\mathrm{F}(\mathrm{b}), \mathrm{M}(\mathrm{b})$, and $\mathrm{M}(\mathrm{c})$ are large). This means that the GWL difference was large

192 just after and 22 hours after both foreshock and main-shock. The GWL difference was as well large between 2 days and 1 day after the main-shock.

Clusters 3, 4, and 5 represent the mid- to downstream area with well groups 1, 2, and 14, respectively. $\mathrm{F}(\mathrm{c})$ and $\mathrm{M}(\mathrm{a})$ are quite large. The GWL difference between the 2 nd and 1 st day after foreshock as well. the earthquakes was large. 
Clusters 8 and 11 are related to both sides of the downstream to midstream area with 6 and 4

wells, respectively. $\mathrm{F}(\mathrm{a})$ and $\mathrm{M}(\mathrm{a})$ are small and $\mathrm{F}(\mathrm{b})$ and $\mathrm{M}(\mathrm{b})$ relatively large. The GWL difference before and after earthquakes was small, and relatively large just after and 22 hours after earthquakes.

205 GWL change (M(c) is relatively large). These areas represent deep wells in the confined aquifer except for

206 cluster 9. The mechanism for sustained GWL change is mainly from earthquake-enhanced permeability,

207 because the transmission of pore pressure from the source to certain wells occurs with different distance

208 and thus, needs different time. This is probably the reason why GWL response time is different from right

209 after earthquake and 22 hours after as well as after 1 day and 2 days. The degree of GWL change is probably

210 influenced by well depth, hydrogeological characteristics, and seismic frequency. This indicates very

211 complex geophysical relationships. Generally, different clusters represent different GWL response in terms

212 of time difference from seismic waves and degree of change. Looking at the case when M(a) is larger than

$213 \mathrm{~F}(\mathrm{a})$ (clusters 5, 6, 8, 9, and 11), the degree of GWL change may be affected by earthquake magnitude under

214 similar hypocentral distance (fault location of inducing foreshock and main-shock is closer) (Wang and

215 Chia 2008). This is due to the fact that seismic energy density increases with larger earthquake magnitude.

\section{GWL-change related to clusters}

218 In order to analyze GWL-change characteristics for each cluster, the data were standardized using

219 maximum and minimum of the change according to: 


$$
\bar{h}=\frac{h-h_{\min }}{h_{\max }-h_{\min }}
$$

221 where $h$ is GWL, $h_{\max }$ and $h_{\min }$ are maximum and minimum GWL, respectively, and $\bar{h}$ is

standardized GWL. To explore annual variation patterns of GWL change for each cluster, the time scale of

data was set to one year. Unfortunately, 8 out the 64 wells did not have a full year record as the earthquake

caused a power failure and disruption of data recording for these wells. Thus, we used the remaining 56 recover to average levels as seen in cluster 2 . This is consistent with the assessment from the radar-charts. For clusters 2 and 7, the GWL decreased $0.69 \mathrm{~m}$ and $0.13 \mathrm{~m}$ in May compared to the ten-year average,

For cluster 1 (5 wells), a general GWL decline occurred in April and August, the GWL tends to return to its initial state. Compared to the ten-year average, the drop of GWL in April is clearly explained by the earthquakes (foreshock and main-shock). The drop of GWL in August was due to the unusually small precipitation during this month. The GWL declined $0.17 \mathrm{~m}$ in April as compared to the ten-year average.

For cluster $2(1$ well) and 7 (3 wells), the earthquake delayed the general GWL recovery due to increasing rainfall. The maximum GWL drop occurred in May and continued until June. After this, GWL recovered due to rainfall. However, the earthquake effects continued to sustain a low GWL and it did not respectively. 
In the case of cluster 3 (1 well), 4 ( 2 wells), and 5 (13 wells), the general GWL decline occurred

241 in April and August similar to cluster 1. For cluster 3, the GWL decline continued until December and did

242 not recover to the initial level. The GWL reduced by $0.55 \mathrm{~m}$ in December compared to the ten-year average.

243 However, for clusters 4 and 5, the GWL gently increased after the earthquakes, then gradually tended to

244 return to initial level. The tendency of GWL recovery from summer to winter is similar to the 10-year

average GWL variation. In the same manner, cluster 4 and 5, display April GWLs in the same range as the ten-year average $(0.03 \mathrm{~m}$ and $0.01 \mathrm{~m}$, respectively).

For cluster 6 (3 wells), 9 (14 wells), and 12 (5 wells), the GWL variation is similar to the general pattern of the 10-year average. However, the effect of the earthquakes is still noticeable. After the initial drop due to the earthquake, the GWL rapidly increased just after the earthquake and then tended to gradually decrease from September. Obviously, these clusters had higher GWL after the earthquake than before. All wells in cluster 6 and 12 are deep and located along the upstream-mountain sides. The rapidly increasing

GWLs may be the results of the contribution of mountain-hold groundwater. For cluster 6 and 12, the GWL change exceeded $0.54 \mathrm{~m}$ to $2.94 \mathrm{~m}$ and $0.1 \mathrm{~m}$ to $2.19 \mathrm{~m}$ as compared to the ten-year average during April to September, respectively. As well, cluster 9 also increased $0.1 \mathrm{~m}$ to $0.48 \mathrm{~m}$ from April to September. In the case of cluster 8 (6 wells), GWL decline occurred in April, then slowly increased after the earthquake. The GWL tended to return back to initial levels in August, as well as continuously increase up to October. For cluster 8, the GWL varied from $-0.11 \mathrm{~m}$ to $0.47 \mathrm{~m}$ during April to August as compared to the ten-year average.

For cluster 11 (3 wells), the GWL decline occurred from April to June, then gradually increased 
from July to October. The GWL did not recover to initial levels. This is clear, when comparing to the 10-

261 year average GWL change. For cluster 11, the GWL declined $0.16 \mathrm{~m}$ to $0.17 \mathrm{~m}$ from April to June compared

262 to the ten-year average. In these clusters ( 8 and 11), the GWL peak occurred in October. This peak is also

263 shown in the GWL change for the past ten-year average.

Most of the shallow wells in the unconfined aquifer rapidly recovered to initial GWLs within

several hours to several days. This was due to hydrostatic pressure. However, most of the deep wells in the

confined aquifer needed longer time to recover, in some cases several weeks to several months. According

to Shi et al. (2015), co-seismic GWL-change usually prevails more than one week after the earthquake. On

268 the contrary, co-seismic GWL-change shorter than one week is a transient change. From the annual

variation characteristics such as for clusters 2,7 , and 11 (deep wells except for only one well), the GWL-

decline seems to be sustained over 1-3 months. Shallow wells such as cluster 1, 5, and 9 were also affected

by extremely low rainfall in August. Even if two wells in cluster 4 are deep wells, GWL dropped in August.

272 They were probably affected by adjacent shallow wells.

\section{Spatial distribution of clusters}

275 The spatial distribution of clusters is shown in Fig. 9. Spatial distribution of clusters is reasonably logically

276 arranged, meaning that wells belonging to the same clusters are located at similar locations. A vast majority

277 of the shallow wells are classified into cluster 5 (downstream) and 9 (midstream). These general cluster

278 characteristics pertain a before and after GWL difference that was large for the main-shock, but small for

279 the foreshock. After the earthquake, the GWL-change was comparatively small and finally returned back 
to initial levels. Some of the deep wells are classified into cluster 6 and 12 (upstream-mountainside). These general cluster characteristics involve relatively large GWL difference 2 days and 1day after both foreshock and main-shock. As these wells are located on the mountainside, the rapid rise in GWL was probably fed by mountain-originating groundwater affected by tremor. Due to this, the GWL change was sustained several weeks to several months.

\section{Conclusions}

To explore transient spatiotemporal variation characteristics in GWL-change induced by earthquakes, SOM

291 GWL gently increased after the earthquake, then tended to stabilize around the initial level. Upstream deep

292 wells were classified into cluster 6 and 12. This group showed relatively large difference in water level

293 from 1 to 2 days after the earthquakes. The GWL rapidly increased just after the earthquake, then tended to

294 gradually decrease from September. Cluster 1 displayed small difference in water level just after and 22 295 hours after the earthquake. The observed wells could be clearly classified into 12 clusters. This information can be used by

297 local governments and water supply managers to better plan appropriate groundwater management in case

298 of a coming earthquake. For example, cluster 1 shows earthquake effects in April but the GWL recovered by December. Consequently, it may be expected that groundwater levels will return to normal within a year. 
300 In the case of cluster 2 and 7, the GWL did not recover to initial levels and the earthquake effects continued

301 for a long period. Thus, large groundwater withdrawal from these wells may need to halt for several years

302 to protect water resources. In the case of cluster 3, 4, and 5, we need to continue GWL monitoring until

303 recovery can be seen, because GWL did not recover to initial levels. However, in the case of cluster 6,9 ,

304 and 12, GWL increased compared to the 10-year average due to the contribution of mountain-hold water.

305 Consequently, these wells can be used for emergency demand.

The findings in this paper have improved the physical understanding on how earthquakes affect

307 the groundwater environment. It is as well important to understand how earthquakes may affect the

308 chemical quality of the drinking water supply. Thus, in future research, we will extend the analyses to longer

309 timescales for GWL change as affected by earthquakes and in addition include groundwater chemistry in

310 the analyses (Cox et al. 2012; Shi et al. 2015).

312 Acknowledgements This work was financially supported by JSPS KAKENHI under Grant No.

313 JP17H01861 and SUNTORY Kumamoto groundwater research project.

\section{References}

316 Bedoya D, Novotny V, Manolakos ES (2009) Instream and offstream environmental conditions and stream biotic integrity. Importance of scale and site similarities for learning and prediction. Ecol Modell 220:2393-2406. doi: 10.1016/j.ecolmodel.2009.06.017 
during the 2016 Amatrice-Norcia seismic sequence (central Italy). Sci Rep7:1-12.

doi: $10.1038 / \mathrm{s} 41598-017-11990-8$

Cox SC, Rutter HK, Sims A, Manga M, Weir JJ, Ezzy T, White PA, Horton TW, Scott D (2012) Hydrological effects of the $\mathrm{M}_{\mathrm{w}}$ 7.1 Darfield (Canterbury) earthquake, 4 September 2010, New Zealand. New Zeal J Geol Geophys 55:231-247. doi: $10.1080 / 00288306.2012 .680474$

Chia Y, Chiu JJ, Chiang YH, Lee TP, Liu CW (2008) Spatial and temporal changes of groundwater level induced by thrust faulting. Pure Appl Geophys 165:5-16. doi: 10.1007/s00024-007-0293-5

Chia Y, Wang YS, Chiu JJ, Liu CW (2001) Changes of groundwater level due to the 1999 Chi-Chi earthquake in the Choshui River alluvial fan in Taiwan. Bull Seismol Soc Am 91:1062-1068. doi: 10.1785/0120000726

García HL, González IM (2004) Self-organizing map and clustering for wastewater treatment monitoring. Eng Appl Artif Intell 17:215-225. doi: 10.1016/j.engappai.2004.03.004

Hentati A, Kawamura A, Amaguchi H, Iseri Y (2010) Evaluation of sedimentation vulnerability at small hillside reservoirs in the semi-arid region of Tunisia using the Self-Organizing Map. 
Geomorphology 122:56-64.

doi: 10.1016/j.geomorph.2010.05.013

Hosono T, Hartmann J, Louvat P, Amann T, Washington KE, West AJ, Okumura K, Böttcher ME, Gaillardet J (2018) Earthquake-induced structural deformations enhance long-term solute fluxes from active volcanic systems. Sci Rep 8:14809. doi: $10.1038 / \mathrm{s} 41598-018-32735-1$

Hosono T, Tokunaga T, Kagabu M, Nakata H, Orishikida T, Lin IT, Shimada J (2013) The use of $\delta{ }^{15} \mathrm{~N}$ and $\delta{ }^{18} \mathrm{O}$ tracers with an understanding of groundwater flow dynamics for evaluating the origins and attenuation mechanisms of nitrate pollution. Water Res 47:2661-2675. doi: 10.1016/j.watres.2013.02.020 doi: $10.1016 /$ j.watres.2014.02.005

Hossain S, Hosono T, Ide K, Matsunaga M, Shimada J (2016a) Redox processes and occurrence of arsenic in a volcanic aquifer system of Kumamoto Area, Japan. Environ Earth Sci 75:1-19. doi: $10.1007 / \mathrm{s} 12665-016-5557-\mathrm{x}$

Hossain S, Hosono T, Yang H, Shimada J (2016b) Geochemical processes controlling fluoride enrichment in groundwater at the western part of Kumamoto Area, Japan. Water Air Soil Pollut 227:385. 
Ishihara S, Kawamura A, Amaguchi H, Takasaki T, Kawai M (2013) Evaluation of characteristics of groundwater level fluctuation in Tokyo by the 2011 off the Pacific coast of Tohoku Earthquake using self-organizing maps. Journal of Japan Society of Civil Engineers, Ser. BI (Hydraulic Engineering) 69(4): I_541-I_546.

Japan Meteorological Agency (2018) Weather observation data. Japan Meteorological Agency Web. http://www.jma.go.jp/jma/index.html. Accessed 16 November 2018

Jin YH, Kawamura A, Park SC, Nakagawa N, Amaguchi H, Olsson J (2011) Spatiotemporal classification of environmental monitoring data in the Yeongsan River basin, Korea, using self-organizing maps. J Environ Monit 13: 2886-2894. doi: $10.1039 / \mathrm{c} 1 \mathrm{em} 10132 \mathrm{c}$

Kagabu M, Matsunaga M, Ide K, Momoshima N, Shimada J (2017) Groundwater age determination using 38 
Kohonen T (2001) Self-organizing maps, 3rd edn. Springer, Berlin

Liu C-Y, Chia Y, Chuang P-Y, Chiu Y-C, Tseng T-L (2018) Impacts of hydrogeological characteristics on groundwater-level changes induced by earthquakes. Hydrogeol J 26:451-465. doi: 10.1007/s10040-017-1684-z

Miyoshi M, Furukawa K, Shinmura T, Shimono M, Hasenaka T, (2009) Petrography and whole-rock geochemistry of pre-Aso lavas from the caldera wall of Aso volcano, central Kyushu. Journal of the Geological Society of Japan 115:672-687 (in Japanese with English abstract). https://doi.org/10.5575/geosoc.115.672

Nakagawa K, Amano H, Kawamura A, Berndtsson R (2017) Classification of groundwater chemistry in Shimabara, using self-organizing maps. Hydrol Res 48:840-850. https://doi.org/10.2166/nh.2016.072

Nguyen TT, Kawamura A, Tong TN, Nakagawa N, Amaguchi H, Gilbuena R (2014) Spatial classification of grovundwater monitoring data in the Red River Delta, Vietnam using self-organizing maps. Annual Journal of Hydraulic Engineering, JSCE 70(4): I_241-I_246. https://doi.org/10.2208/jscejhe.70.I_241

Nguyen TT, Kawamura A, Tong TN, Nakagawa N, Amaguchi H, Gilbuena R (2015) Clustering spatioseasonal hydrogeochemical data using self-organizing maps for groundwater quality assessment in the Red River Delta, Vietnam. J Hydrol 522: 661-673. 
Roeloffs EA (1988) Hydrologic precursors to earthquakes: A review. Pure Appl Geophys PAGEOPH 126:177-209.

doi: 10.1007/BF00878996

Shirahama Y, Yoshimi M, Awata Y, Maruyama T, Azuma T, Miyashita Y, Mori H, Imanishi K, Takeda N,

Ochi T, Otsubo M, Asahina D, Miyakawa A (2016) Characteristics of the surface ruptures associated with the 2016 Kumamoto earthquake sequence, central Kyushu, Japan. Earth, Planets Sp 68:1-12.

doi: 10.1186/s40623-016-0559-1

Shi Z, Wang G, Manga M, Wang CY (2015) Mechanism of co-seismic water level change following four great earthquakes-insights from co-seismic responses throughout the Chinese mainland. Earth and Planet Sci Lett 430:66-74.

doi: 10.1016/j.epsl.2015.08.012

Tsunogai U, Wakita H (1995) Precursory chemical changes in ground water: Kobe earthquake, Japan. Science 269:61-63.

doi: $10.1126 /$ science.269.5220.61

Vesanto J, Himberg J, Alhoniemi E, Parahankangas J (2000) SOM Toolbox for Matlab 5, Helsinki University of Technology Report A57

Wang CY, Chia Y (2008) Mechanism of water level changes during earthquakes: Near field versus 
intermediate field. Geophys Res Lett 35:1-5.

doi: 10.1029/2008GL034227

412 Wang CY, Manga M (2010) Hydrologic responses to earthquakes and a general metric. Front Geofluids 206-216. doi: 10.1016/j.chemosphere.2014.04.020

424 Yu ZQ, Amano H, Nakagawa K, Berndtsson R (2018) Hydrogeochemical evolution of groundwater in a

Manga M, Wang C-Y (2015) Earthquake Hydrology. In: Gerald Schubert (ed), Treatise on Geophysics, 2nd edn. Vol 4. Elsevier, Oxford, pp 305-328

Yamazaki F, Liu W (2016) Remote sensing technologies for post-earthquake damage assessment: a case study on the 2016 Kumamoto earthquake. 6th ASIA Conference on Earthquake Engineering, At Cebu City, Philippines.

Yu H, Song Y, Liu R, Pan H, Xiang L, Qian F (2014) Identifying changes in dissolved organic matter content and characteristics by fluorescence spectroscopy coupled with self-organizing map and classification and regression tree analysis during wastewater treatment. Chemosphere 113: 79-86. Quaternary sediment and Cretaceous sandstone unconfined aquifer in Northwestern China. Environ Earth Sci 77: 629. doi: 10.1007/s12665-018-7816-5 
429 Figure 1 Monitoring wells in the Kumamoto area

430 Figure 2 GWL-change in representative wells in connection to the Kumamoto earthquake sequence.

431 (A-J indicate point-in-time to calculate water level variation before and after foreshock and main-shock.

432 By using point-in-time (A-J), six variables were defined as $F(a):(B-A), F(b):(C-B), F(c):(E-D), M(a):(G-$

433 F), M(b):(H-G), and M(c):(J-I), respectively)

434 Figure 3 Component planes for $(\mathrm{F}(\mathrm{a}), \mathrm{F}(\mathrm{b}), \mathrm{F}(\mathrm{c}), \mathrm{M}(\mathrm{a}), \mathrm{M}(\mathrm{b})$, and $\mathrm{M}(\mathrm{c}))$

435 Figure 4 Spatial distribution characteristics of GWL difference by use of the six variables $(F(a), F(b)$,

$436 \mathrm{~F}(\mathrm{c}), \mathrm{M}(\mathrm{a}), \mathrm{M}(\mathrm{b})$, and $\mathrm{M}(\mathrm{c}))$

437 Figure 5 Visualized map of the twelve clusters by the SOM

438 Figure 6 Dendrogram for respective group using node numbers of SOM

439 Figure 7 Radar-chart for each cluster

440 Figure 8 Annual variation pattern for mean GWL of each cluster

441 Figure 9 Cluster classification for Kumamoto monitoring wells 


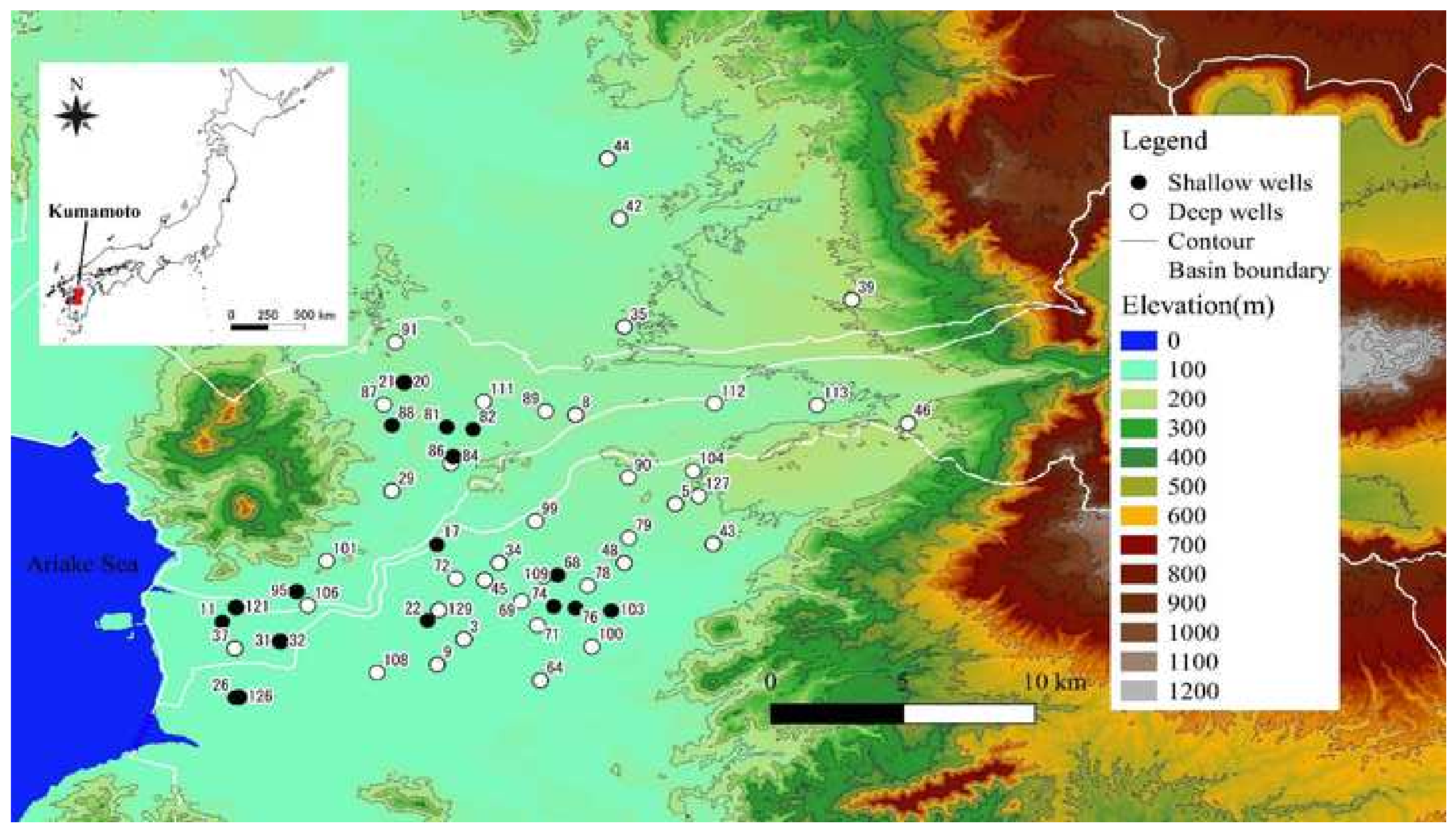




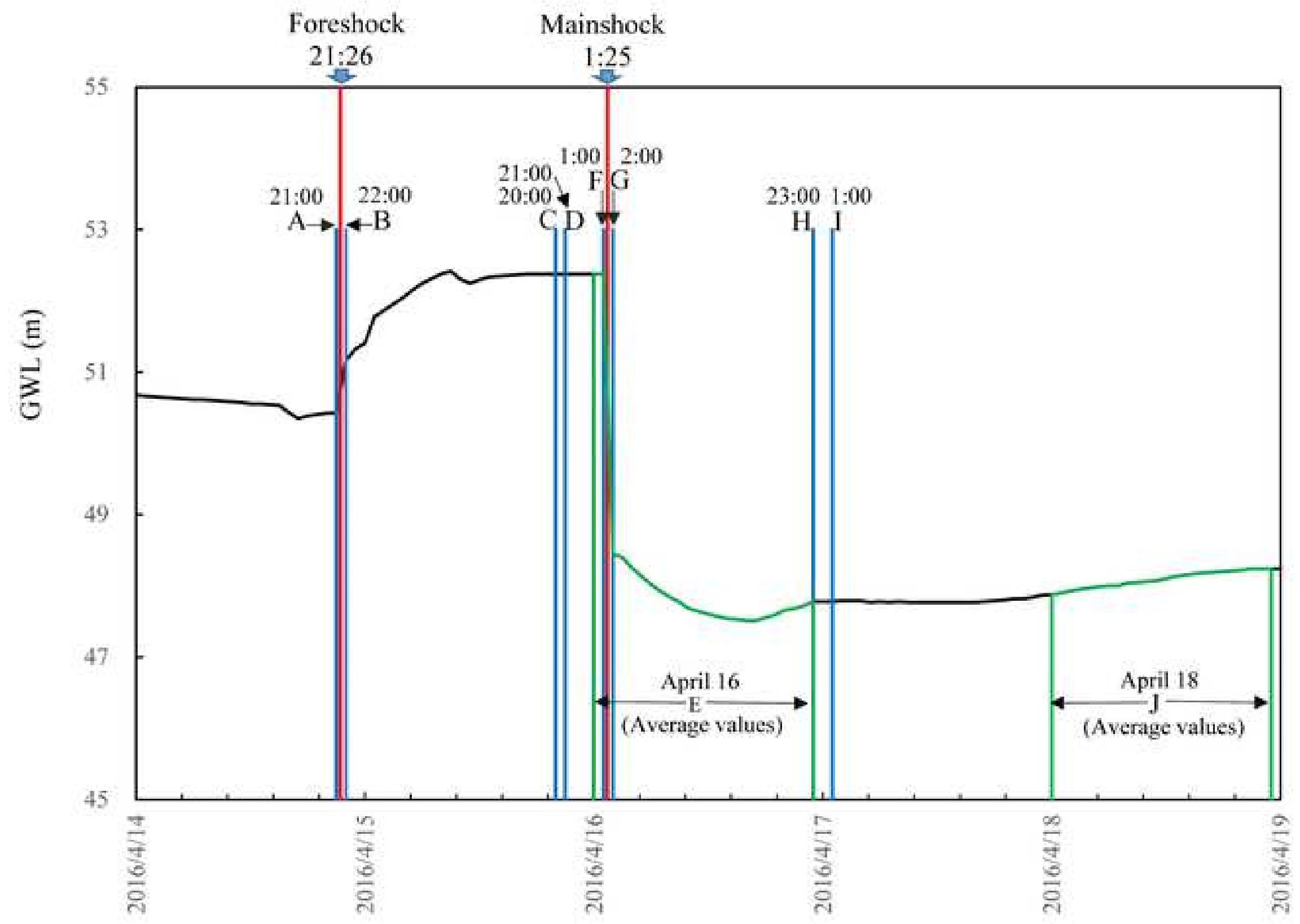


$F(a)$

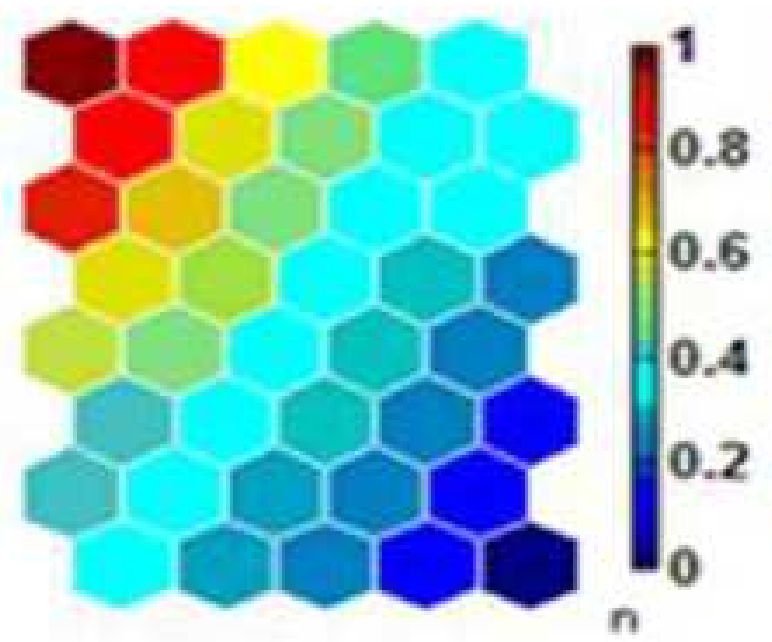

M(a)

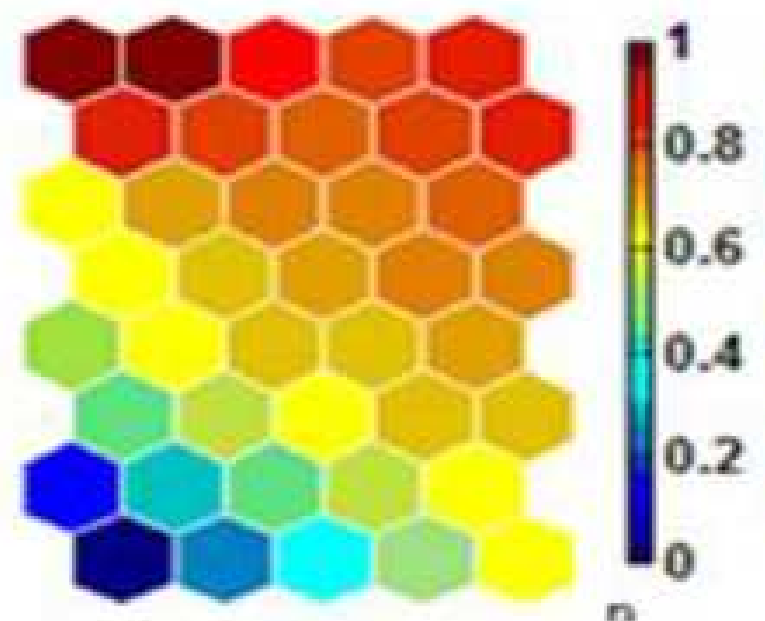

n
$F(b)$

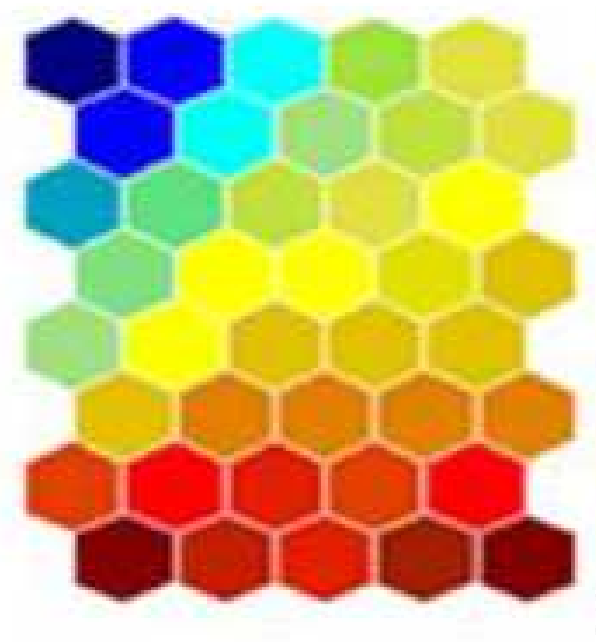

M(b)

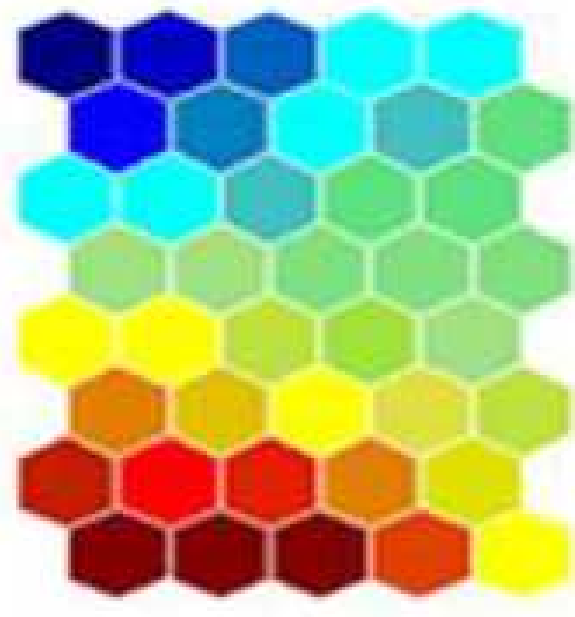

$F(c)$
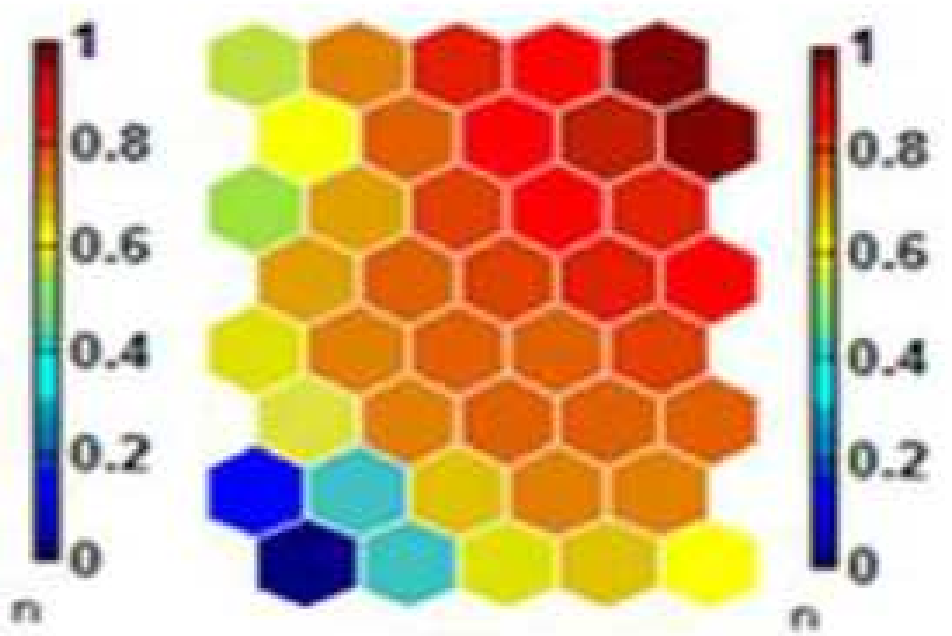

M(c)
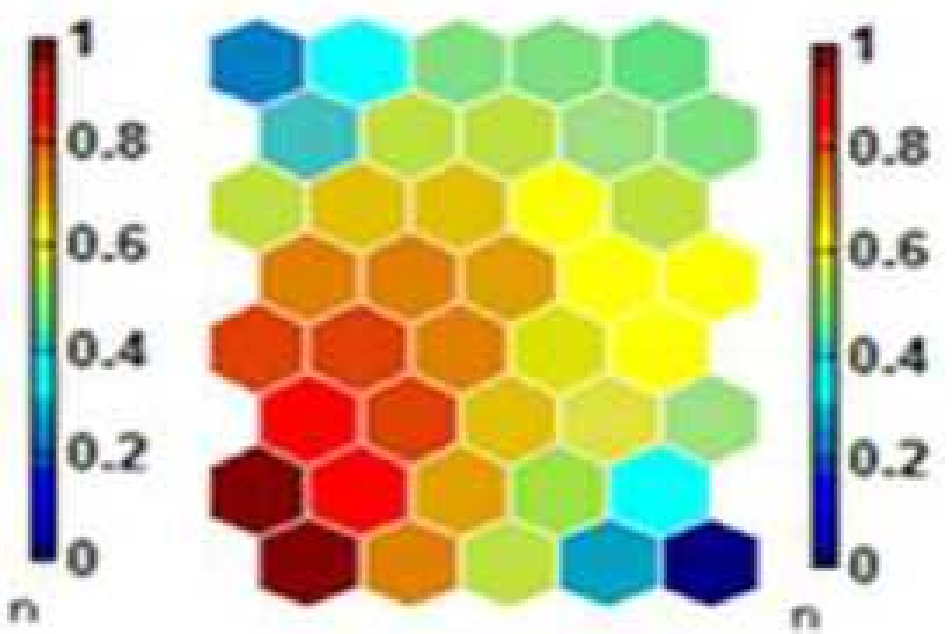


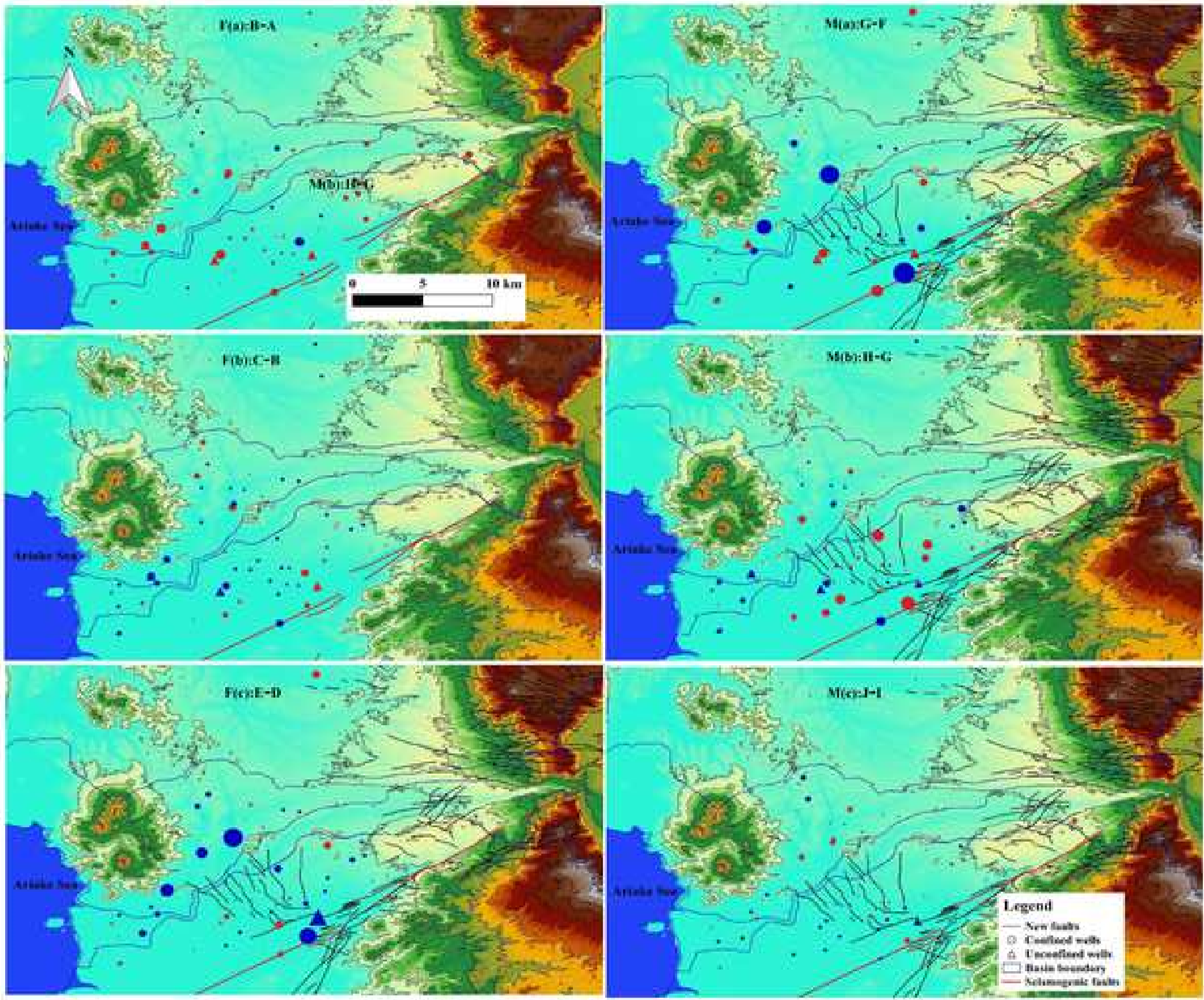

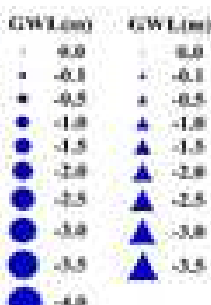

:

: of

is 4 is

$0: 5$ 


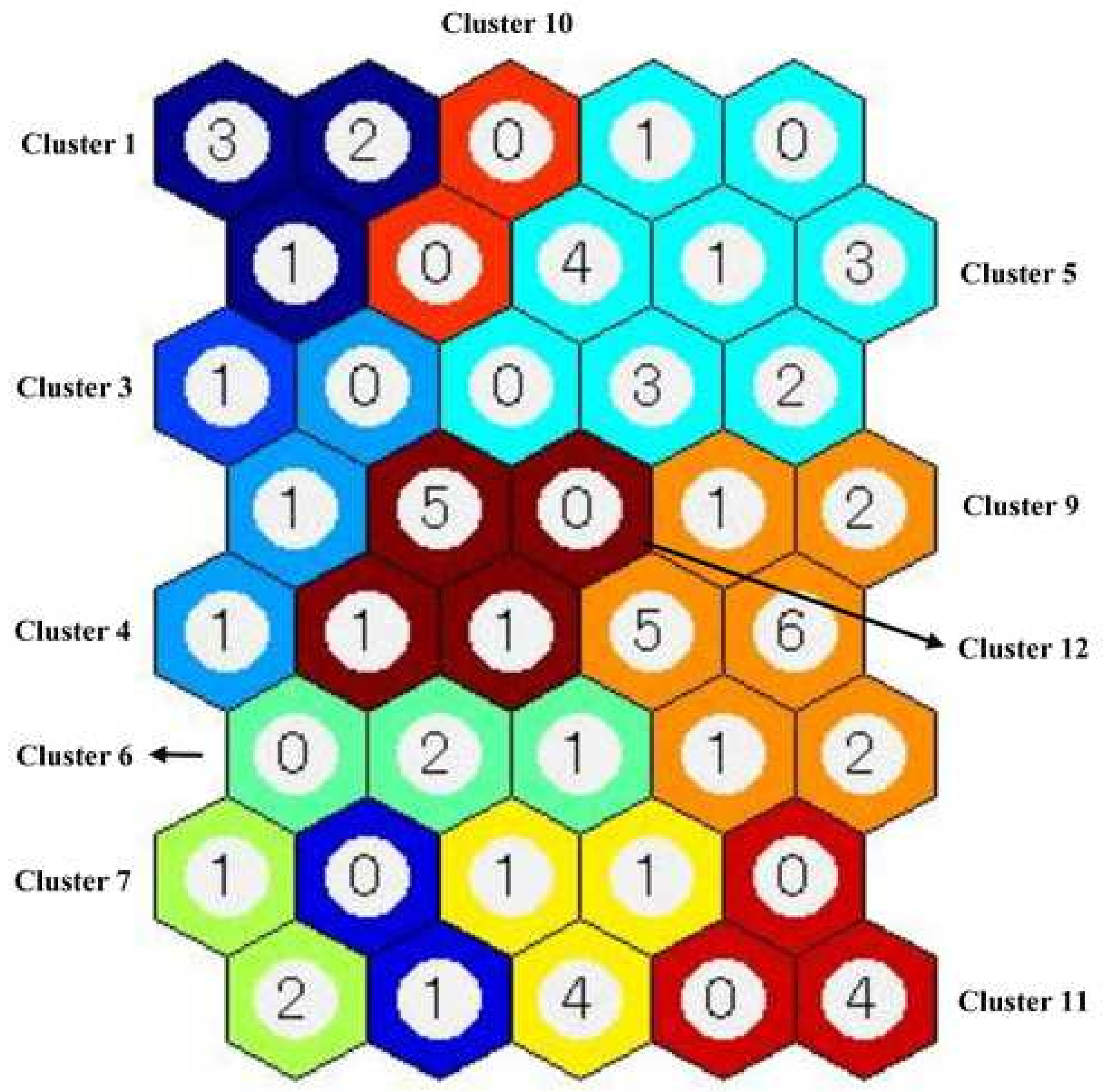

Cluster 2 Cluster 8 


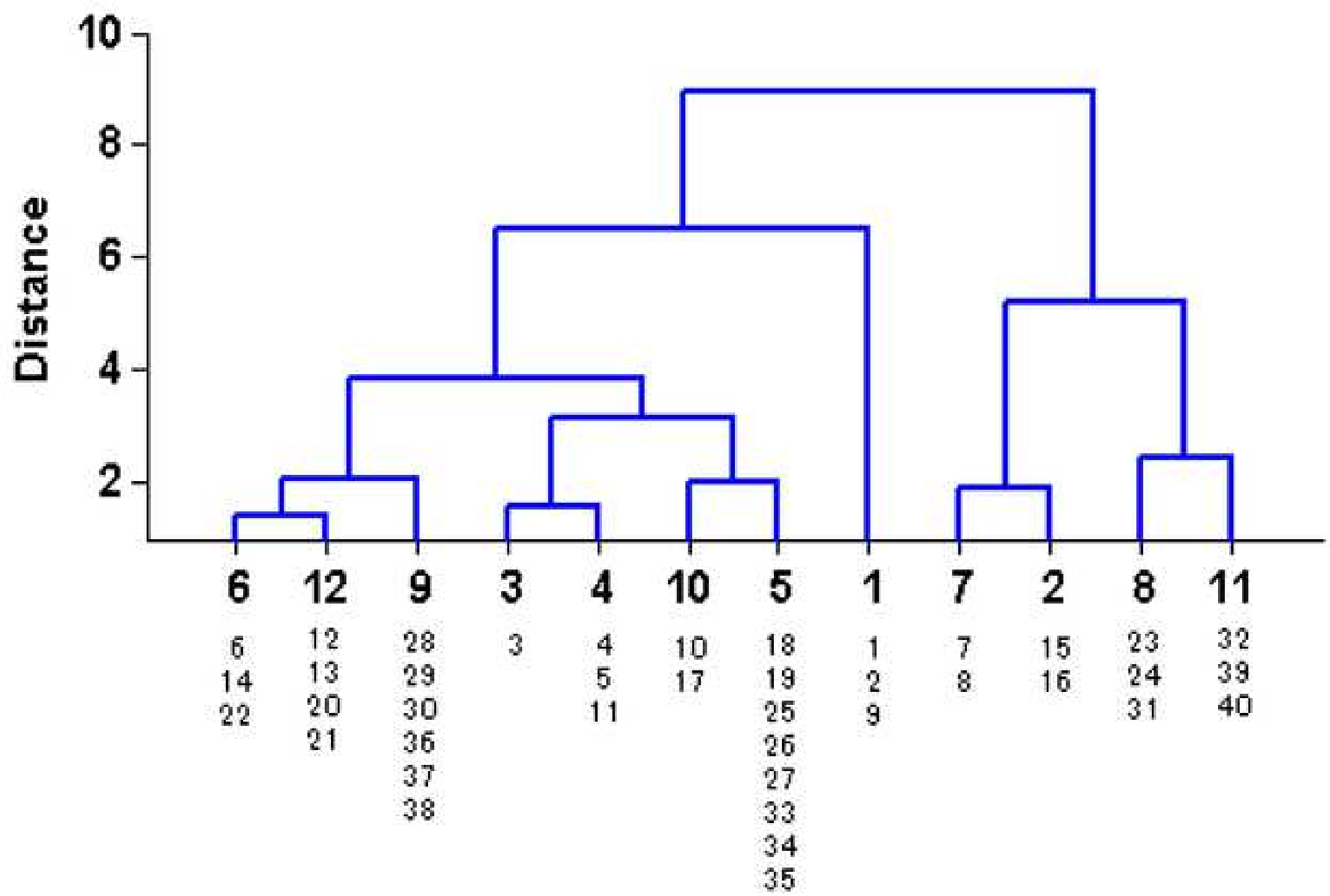



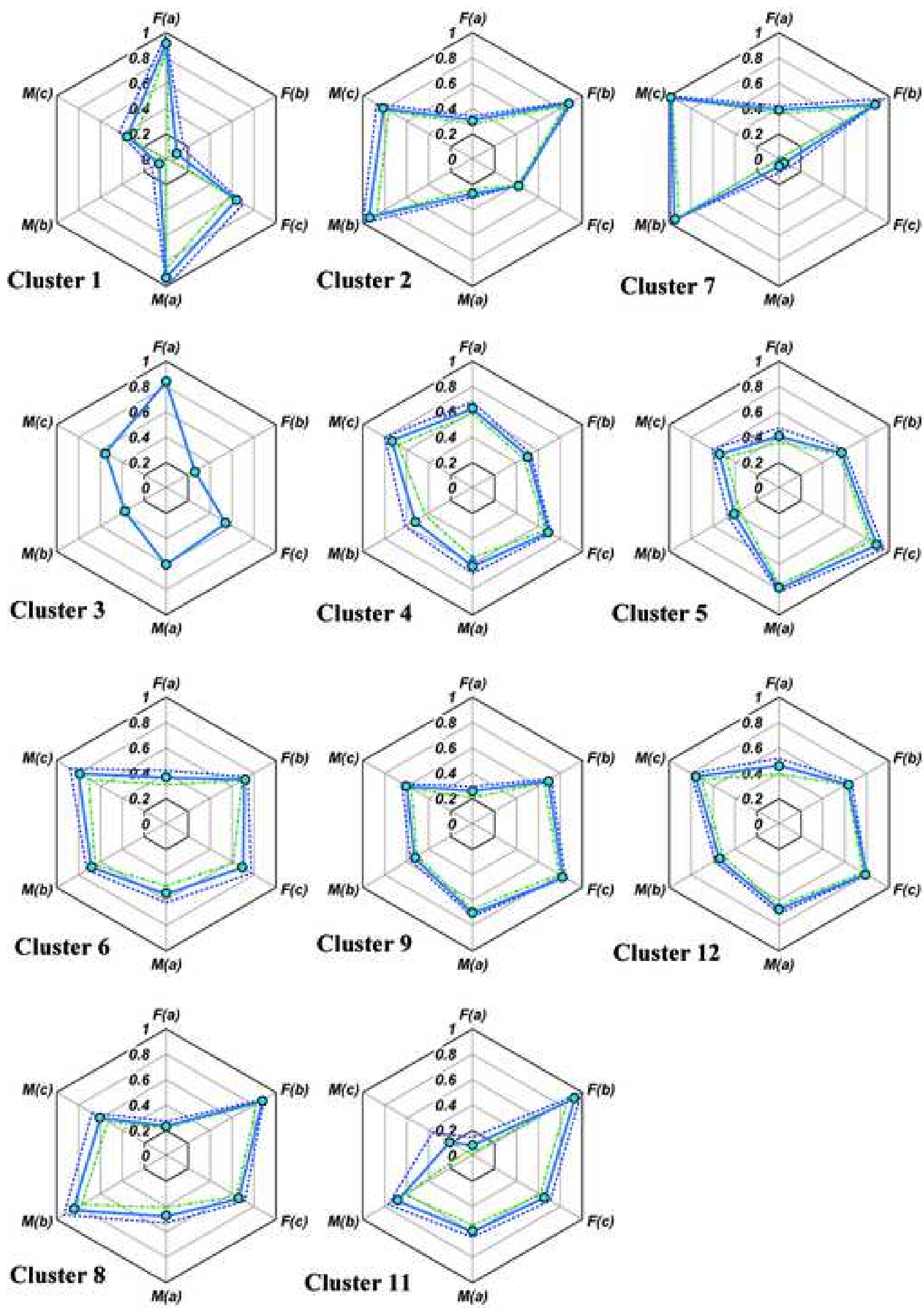

$F(c)$ 

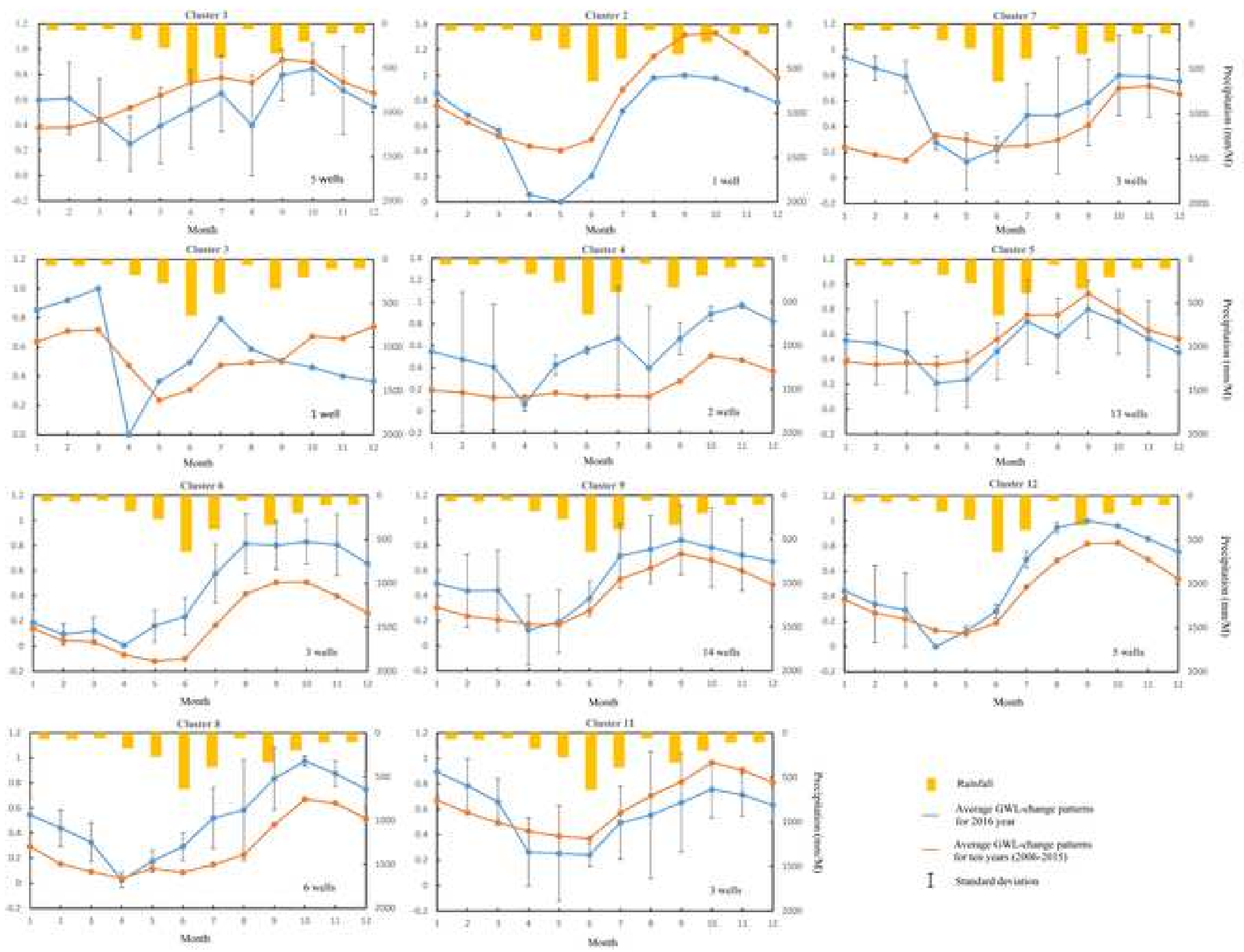

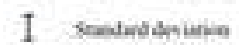




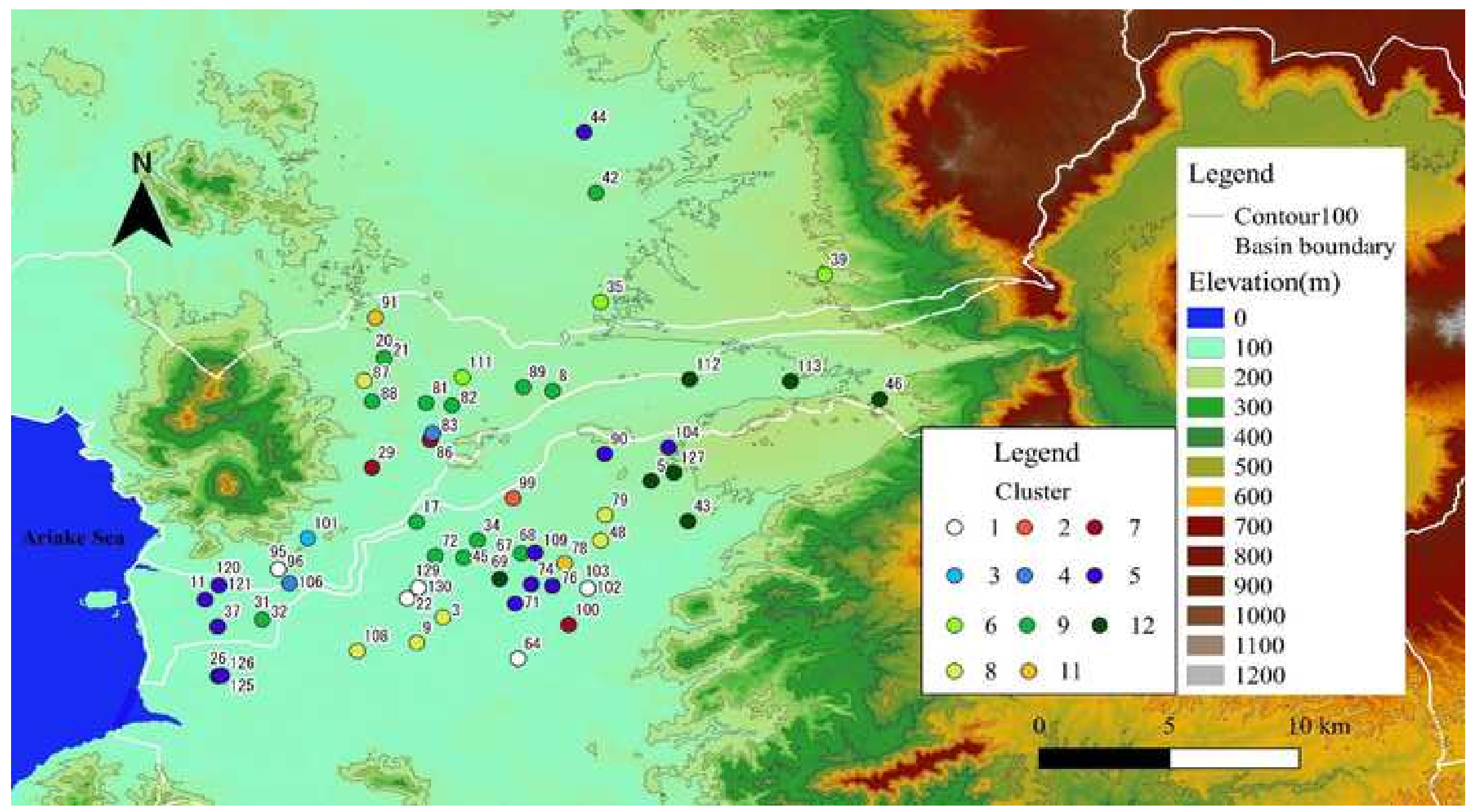

